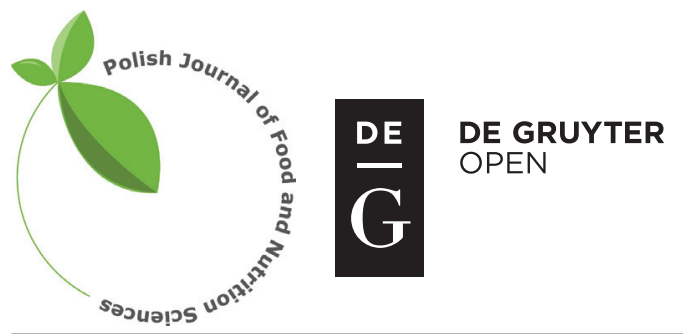

Pol. J. Food Nutr. Sci., 2016, Vol. 66, No. 2, pp. 119-127

DOI: $10.1515 /$ pjfns-2016-0004 http://journal.pan.olsztyn.pl

Original article

Section: Nutritional Research

\title{
Impact of Innovation on Consumers Liking and Willingness to Pay for Traditional Sausages
}

\author{
Sylwia Żakowska-Biemans ${ }^{1^{*}}$, Marta Sajdakowska ${ }^{1}$, Sylvie Issanchou ${ }^{2,3,4}$ \\ ${ }^{1}$ Faculty of Human Nutrition and Consumer Sciences, Department of Organization and Consumption Economics, Warsaw \\ University of Life Sciences - SGGW, ul. Nowoursynowska 166, 02-787 Warszawa, Poland \\ ${ }^{2}$ CNRS, UMR6265 Centre des Sciences du Goût et de l'Alimentation, F2100 Dijon, France \\ ${ }^{3} I N R A$, UMR1324 Centre des Sciences du Goût et de l'Alimentation, F2100 Dijon, France \\ ${ }^{4}$ Univ. Bourgogne Franche-Comté, UMR Centre des Sciences du Goût et de l'Alimentation, F2100 Dijon, France
}

Key words: traditional food, consumer acceptance, innovation, experimental auction, willingness to pay

The main objective of the study was to evaluate Polish consumers' liking and willingness to pay for innovations in traditional sausages "Kabanos". The study also attempted to determine whether regional differences may influence acceptance of innovations and the willingness to pay for such products. As both sensory factors and prices are important in food choice decisions, the methodological approach combined hedonic liking and experimental auctions. The study involved 221 consumers of traditional pork sausages who evaluated intrinsic and extrinsic product attributes in blind (tasting only), expectancy (product information only) and fully informed (tasting and product information) experimental conditions. The results show that acceptance of innovation in traditional sausages is determined by the type of innovation proposed. Innovation related to extrinsic attributes like packaging i.e. biodegradable packaging seem to be the most welcome regardless experimental conditions while innovations improving healthiness of traditional sausages but violating their sensory properties i.e. lower salt level tend to be disapproved. There are regional differences observed in acceptance and willingness to pay for innovative variants of Kabanos. In general, consumers in Warsaw are more inclined to pay more for innovative variants of Kabanos than consumers in Cracow. Participants from the two regions had also different hedonic reactions towards organic and spicy variant of Kabanos. Prior research concerning acceptance of innovation in traditional food products in Poland is scarce. Therefore, such information is particularly pertinent to SMEs and distributors operating in traditional food sector to support innovation and development of adequate communication strategies.

\section{INTRODUCTION}

The ongoing diversification of consumer expectations regarding food, implied both by globalisation and striving to preserve own cultural values and national identity, facilitates the interest in traditional food products (TFP). The unique values of traditional food result from combination of specific characteristics of raw materials, processing methods and the place of origin, which in turn influences genuineness of that food category. Traditional food is an important element of European culture and identity, thus contributing to the socio-economic sustainability of European rural areas and increasing the variety of food choice for consumers.

Consumer demand for traditional food rises in many western economies [Trichopoulou et al., 2007] that is implied by the unanimous positive image consumers have of traditional foods [Guerrero et al., 2009; Almli et al., 2011b]. To facilitate development of traditional food market it is essential to adjust the traditional food offer to the expectations of contemporary consumers who, on the one hand, declare their inclination for buying traditional food, but on the other hand, seek products with functional and convenience attri-

\footnotetext{
* Corresponding Author: E-mail: sylwia_zakowska_biemans@sggw.pl aging that prolonged the shelf life and the sensory quality.

butes that result from modern ways of food processing, packaging and distribution [Gellynck \& Molnár, 2009]. In order to respond to these diverse and often contradictory consumers' values, it is essential to create innovative traditional food products and innovations throughout the food chain. However, tradition and innovation are considered antonyms, which makes innovating traditional food products very challenging [Gellynck \& Kühne, 2008; Jordana, 2000]. Nevertheless, to increase their market share, traditional food products need to be improved by introducing innovations in line with the European consumers' demand from different perspectives, including health, safety, taste and convenience characteristics [Cayot, 2007].

In general, the acceptance of an innovation depends on the innovation itself as well as on the carrier product to which it is applied, especially in the food domain [Guerrero et al., 2010]. Vanhonacker et al. [2013] and Almli et al. [2011a] indicated that the characteristic features of offered innovations are important factors influencing their perception among consumers. The research of Guerrero et al. [2009] among consumers from six European countries shows that consumers generally accept innovations in TFPs that tend to improve the health and safety of the product, and pack- 
Suggested innovations that significantly changed the intrinsic product characteristics were commonly disapproved. The results of exploratory research among Polish consumers using focus group interviews show that they pertain to the possibility of introduction of innovations in TFP rather sceptically [Gutkowska et al., 2009].

There are numerous studies on cross cultural differences in the perception of traditional food and acceptance of innovation in TFP [Guerrero et al., 2009, 2010; Almli et al., 2011a,b; Vanhonacker et al., 2013]. The image of traditional food is positive among European consumers but there are cross-cultural differences in the conceptualization of TFP [Guerrero et al., 2009]. For Polish consumers, tradition in foods was mostly linked to sensory properties and family, while for Italians the most frequent association was homemade [Guerrero et al., 2010]. According to Vanhonacker et al. [2010a], while the Poles define traditional food mainly as specialty dishes consumed on festive occasions, the Belgians mostly consider traditional food as familiar food of daily character. The research of Almli et al. [2011a] shows that taste is an attribute of primary importance while conceptualizing TFP. Polish consumers characterise TFP by a good and special taste, a high yet not highly consistent quality, a high environmental friendliness, a good support for the local economy, a high preparation time and rather high prices. Belgian consumers focus more on good taste, a high quality and a high availability while Norwegians characterise TFP with a good taste, a high quality, a relatively low healthiness, a high safety and a long preparation time.

Guerrero et al. [2009] found out in their qualitative research that Polish consumers were the most reluctant to accept innovations in food in general but more specific with regard to traditional food. Study of Kühne et al. [2010] reveals that Polish consumers appeared to be more open to innovations in traditional food, whereas Belgian consumers were more innovation averse. However, Kühne et al. [2010] covered in their study innovations that are positively connoted and do not significantly change the intrinsic attributes of TFP that certainly affect the results. As Almli et al. [2011a] pointed out there are cross-cultural differences in adoption of product related innovation and e.g. Norway may focus on developing healthier TFP, such as low-fat and/or salt-reduced meat products while strong environmental friendly, supportive of local economy model from Poland may be exported to other countries, especially Norway and Belgium.

Poland like many other European countries has experienced numerous occupations by different cultures over the centuries and particularly Russian, German and the former Austrian-Hungarian Monarchy. All of these peoples, particularly if they had stayed in a country for some time, left their culinary traces [Weichselbaum et al., 2009]. Despite the fact that "national culture" is the set of collective beliefs and values that distinguishes people of one nationality from those of another [Hofstede, 2001], regional cultural differences might affect the perception of TFP and the willingness to accept innovation in TFP that in turn might have implications for the stakeholders involved in this sector.

To get insight into drivers of innovation in TFPs it is essential to go beyond studying consumers' attitudes towards innovation. Thus, experiments with consumers combining sensory and economic measures seem very promising to get insight into drivers of innovation in TFPs and eliciting willingness to pay values in order to obtain a more accurate anticipation of the market potential for traditional food.

Therefore, the main objective of the study was to evaluate Polish consumers' liking and willingness to pay for innovations in one of the most popular traditional sausages "Kabanos". The study also attempted to determine whether regional differences may influence acceptance of innovations in traditional meat products and the willingness to pay for such foodstuffs.

The remainder of the study is divided into five main sections including introduction, material and methods, results, discussion and conclusions. In the material and methods section appears detailed information on the characteristic features of traditional pork sausage, an overview of the innovation proposed and the research approach using Becker, De Groot and Marschak (BDM) auction mechanism [Becker et al., 1964]. The results of hedonic liking and reservation prices in blind, expectancy and full information condition are presented separately for Warsaw and Cracow. This section provides also results of the attitudinal questionnaire on the image of traditional food and acceptance of innovation in TFP.

\section{MATERIAL AND METHODS}

Kabanos sausage belongs to the commonly used traditional cold meats in Poland [Borowska, 2007]. On 20 October 2011 Commission Implementing Regulation (EC) No 1044/2011 of 19 October 2011 registered Kabanos as traditional specialities guaranteed [Kabanos sausage..., 2011; Official Journal..., 2011]. The name Kabanosy (plural of "Kabanos") expresses the specific character of the product. In the 19th century, in the territory of Poland and Lithuania, a young fattened hog fed extensively with potatoes was called a "kaban", or diminutively "kabanek". The aim of proper feeding was to obtain meat characterised by higher intramuscular fat level. Meat of such fed kaban was delicate and exquisite, and it was customarily referred to as "kabanina". The distinctive feature of Kabanos among other sausages is their taste and aroma. These features result from implementation of seasonings like natural pepper, nutmeg, caraway, as well as smoking process that also intensifies the taste properties of that product. The characteristic feature of Kabanos is also its clearly audible sound of crack when they are broken (the so called 'shot').

To get insight into potential impact of regional differences, the study was conducted in two urban locations: Warsaw and Cracow in 2010 and 2011. The cities differ with both the number of inhabitants and its cultural context. Warsaw, as the capital city, has some characteristics of a metropolis with a large share of immigrant dwellers, a very low unemployment rate and a relatively high level of income per capita and higher expenditure on food [Gutkowska \& Murawska, 2013]. Cracow, located in southern Poland (Małopolska Province), is considered a cultural capital of Poland and the Provincial authorities place particular emphasis on promotion of the regional cultural heritage and actively supports registration 
TABLE 1. Socio-economic characteristic of the consumers' samples in Warsaw and Cracow.

\begin{tabular}{lc|c|c}
\hline Characteristics & Level & $\begin{array}{c}\text { Warsaw } \\
\mathrm{n}=102 \\
(\%)\end{array}$ & $\begin{array}{c}\text { Cracow } \\
\mathrm{n}=119 \\
(\%)\end{array}$ \\
\hline Gender & Men & 27 & 39 \\
& Women & 73 & 61 \\
\hline Age & $20-29$ & 23.5 & 24.4 \\
& $30-39$ & 12.7 & 22.7 \\
& $40-49$ & 15.7 & 17.6 \\
\hline Financial* situation & $50-59$ & 25.5 & 26.9 \\
\hline & $60-72$ & 22.6 & 8.4 \\
\hline Education & Mean & $4.29 \mathrm{~b}^{* *}$ & $4.61^{\mathrm{a}}$ \\
\hline
\end{tabular}

* Scale: $1=$ difficult, 7 = well off; **the difference is significant $[t=2.10$, $\mathrm{p}=0.04]$.

of products with protected designations. In 2015 there were 164 traditional products registered in Małopolska as compared to 88 in Mazovia Province where Warsaw is located [Polish registry..., 2015]. Culinary traditions in Mazovia Province are influenced more by Eastern and Russian cuisine while culinary heritage in Małopolska Province is shaped by the Southern neighbouring countries and particularly the former Austrian-Hungarian Monarchy. Consumers in Cracow are more conservative and could be less inclined to accept innovation in TFP, while consumers in Warsaw are believed to be open to novelties and less devoted to traditional values. As a result they should be more open to innovations, because it is noted that there is a relation between cultural diversity, population density and interest in innovative food products [Sojkin, et al., 2009].

The participants were recruited by a market research agency based on their frequency of traditional food consumption and responsibility for food shopping. There were in total 221 consumers recruited to take part in the study of whom 102 in Warsaw and 119 in Cracow. Demographic characteristics of the consumer samples in Warsaw and Cracow are provided in Table 1. The number of respondents of various age categories differed and a high proportion of respondents who declared high education level was noted in both locations reflecting the profile of traditional food consumers in Poland [Vanhonacker et al., 2010a]. Subjective assessment of income situation was measured on a seven-point interval scale anchored from "difficult" to "well off". This subjective assessment is considered an indicator of socio-economic class [Almli et al., 2011b]. The results show that the consumers from Cracow assessed their financial condition better than the ones from Warsaw.

The proposed innovations in traditional sausage reflect contemporary trends in Polish consumers' food choices and tackle issues like public health benefits and environment protection. The innovation referred to: (1) method of produc- tion - organic, (2) health benefits - reduced salt level, (3) taste - spicy variant, and (4) packaging - biodegradable packaging. There were 4 innovative variants and a control sample (referred as traditional) of Kabanos prepared exclusively for the experiment by the processing company specialised in traditional food. In the case of organic Kabanos, there have been no changes in the recipe, whereas the non-organic ingredients were replaced with organic ones, so as that, the obtained product would fully meet the criteria of organic food production. The observed increasing interest in organic food among Polish consumers was the decisive factor that influenced the choice of that innovation. Polish consumers have very positive attitude to organic food assigning it with attributes such as "healthy", "natural", and "safe" [Z̈akowska-Biemans, 2011]. However, the question remains whether the use of organic ingredients in production of traditional food may constitute added value in the consumers' opinion and increase acceptance of that product. The innovative varieties of Kabanos with health benefits and spicy taste concerned modification in the original recipe of Kabanos and related to $40 \%$ decrease in salt content (low salt variant) and addition of seasonings like red pepper powder and curry in order to obtain a spicy taste (spicy variant). These innovations respond to two complementary tendencies. On the one hand, the necessity to lower salt consumption is more and more pronounced due to public health concerns like prevention of cardiovascular system diseases and particularly hypertension [Newson et al., 2013]. On the other hand, contemporary consumers seek for new sensory sensations, which is in line with the proposed modification of sensory properties. In the selection of potential innovations, also environmental concerns were covered. Offering Kabanos sausages, that most often are sold in unitary plastic vacuum-packaging, in biodegradable packaging could have positive impact on the perception of consumers and market positioning.

\section{Design of the experiment}

The consumer experiment consisted of five stages: (1) Auction information and training, (2) Blind test (tasting only), (3) Expectations test (product information only), (4) Full information test (tasting and product information combined), and (5) Auction sale. At the end of the session consumers' filled in a short attitudinal questionnaire aimed at getting some insight into their perception of traditional and organic food and attitude towards various type of innovation in traditional food products. Consumers evaluated on a 7-point semantic scale items describing the image of both food categories in terms of overall quality, sensory aspects, healthiness, availability and environmental impact. To evaluate which innovations are in line with their expectation the participants were asked the following question "Could you please indicate which innovations are appropriate for Kabanos? Put x in the proper place in the table, where 1 means "I associate this innovation not at all with Kabanos" and 7 means "I associate this innovation very much with Kabanos".

The method chosen to elicit consumers' willingness to pay was the Becker, De Groot and Marschak (BDM) auction mechanism [Becker et al., 1964]. Advantage of employing the experimental auctions is that a real product and real 
money are used. Therefore, the procedure replicates as closely as possible the actual purchase decision process. At the beginning of each session, it was explained to the consumers that they would evaluate different products in different information conditions and would have to give the maximum price they would accept to pay for a pack of each of the products presented (reservation price). In order to avoid endowment effects and strategic behaviours, consumers were informed that only one situation (that is one product pack in one information condition) would be randomly selected at the end of the set of auctions. It was explained that sale would take place if the price drawn at random, in a distribution similar to the market price distribution, is lower than, or equal to, the price offered by the consumer and the consumer would have to buy the product and to pay for it at the randomly determined price. If the randomly drawn price is higher than the price offered by the consumer, the participant does not buy any product. The key point was to make consumers understand that their best strategy is to submit the true maximum price they would accept to pay for each packaging of Kabanos, i.e. their reservation price. In order to make sure that consumers understood the auction rules correctly, the experimenter presented the case of an imaginary auction for a package of cheese of $300 \mathrm{~g}$. The idea was to present food product different from the target product but in the same price range. Consumers who agreed to participate in the experiment were asked to sign the consent form and received 55 PLN $( \pm 14 €)$.

\section{Evaluation conditions}

\section{Blind test}

Consumers were presented with the samples in a random order without any information about the samples. After tasting a sample, they rated their liking of that product on a $10-\mathrm{cm}$ linear hedonic scale anchored with "I do not like it at all" and "I like it very much". The samples were served cold in a randomised order. Due to the persistent flavour of the product, consumers were given tea and sliced baguettes in order to rinse the mouth.

\section{Expectation test}

Consumers were presented with information about each variant. Labels with the basic mandatory information and additional claims (lower salt content, organic, spicy, biodegradable packaging) were presented. Participants evaluated their expectations after looking at the information included on the packaging but without tasting the sample and submitted their reservation price answering the question "How much are you willing to pay for a $300 \mathrm{~g}$ package of this Kabanos?".

\section{Full information test}

In the full information test participants tasted each variant with the product information provided on the packaging and again, they rated their liking for each variant on the hedonic scale and gave their reservation price. The samples were served in a randomised order in the same conditions as in the blind session. At the end of session participants were asked to fill in an attitudinal questionnaire.

\section{Statistical analysis}

All data were coded in Ms Excel and analysed by using SAS/STAT software, version 9.1 (SAS Institute Inc., Cary, NC, USA, 2002-2003). Two-way ANOVA models with effects of variant, city and consumer within city as a random factor were run for each dependent variable (liking score and willingness to pay) as well as for each test condition. These models included an interaction between city and variant. Since this interaction was significant for each dependent variable and each test condition, two-way ANOVAs were conducted for each variable per city and information condition with effects of variant and consumers (random). To assess the differences in hedonic liking scores and WTP multiple comparisons of means were performed with Bonferroni tests. In order to examine if the differences and similarities between the two cities that we observed on their responses (hedonic liking and reservation price) could be linked to their responses to the attitudinal questionnaire, $t$-tests for continuous variables were performed for the different items of the questionnaires related to the image of traditional and organic food as well as acceptance of innovations tested during the experiment.

\section{RESULTS}

\section{Hedonic liking}

A significant variant effect was observed in Warsaw for each test condition $\left(\mathrm{F}_{4,404}=7.09,6.80\right.$, and 12.08, respectively for blind, expectancy and full information conditions; all $\mathrm{p}$ values $<0.0001)$. However, there are some differences in the ranking of the variants according to the test condition as shown in Figure 1.

In the blind condition, none of the innovations obtained a significantly higher liking score than the traditional variant. The variant in biodegradable packaging (5.90) and the spicy variant (5.39) were as much liked as the traditional variant (5.64). This seems fully justified in the case of the Kabanos in biodegradable packaging as it did not differ from the traditional variant with regard to recipe and sensory properties. On the contrary, two of the tested innovations obtained a lower score than the traditional variant: the low-salt and the organic variants (4.74 and 4.69, respectively). In the expectancy condition, the variant in biodegradable packaging was the most liked (6.17); this liking score was not significantly higher than the scores of the low-salt and the spicy variants (5.74 and 5.82, respectively) but was significantly higher than the score obtained by the traditional variant (5.20). The organic variant was the innovation which induced the lowest expectancy (4.90). In the full information condition, the variant in a biodegradable packaging was the most liked (6.45) as in the expectancy condition; this liking score was not significantly higher than the score of the spicy variant (5.89) but was significantly higher than the score obtained by the traditional variant (5.19). It is noticeable than, in the full information condition, the low-salt variant (4.68) was amongst the least liked variants as in the blind condition. The liking scores of the traditional variant and the organic variant (4.84) were not significantly different from the liking score of the low-salt variant. 


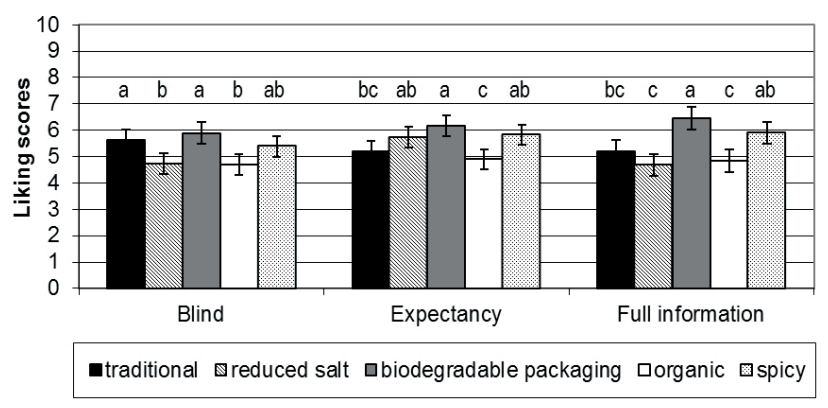

FIGURE 1. Liking scores of Kabanos in the three information conditions in Warsaw $(n=102)$ : means $\pm 95 \% \mathrm{CI}$, values with different letters are significantly different ( $\leq 0.05$, Bonferroni tests).

A significant variant effect was also observed in Cracow for each test condition. However, the effect was less significant in the expectancy and full information conditions than in Warsaw $\left(\mathrm{F}_{4.472}=10.19,3.36\right.$, and 2.40 , and $\mathrm{p}<0.0001$, $\mathrm{p}=0.01$, and $\mathrm{p}=0.05$, respectively for blind, expectancy and full information conditions). There are some differences in the ranking of the variants according to the test condition as shown in Figure 2.

In the blind condition, none of the innovations obtained a significantly higher liking score than the traditional variant. As in Warsaw, the variant in a biodegradable packaging (6.19) was as much liked as the traditional variant (6.09). Consumers in Cracow, as those in Warsaw, gave a lower liking score to the low-salt variant (5.33). Participants in Cracow differed from those in Warsaw concerning their liking of the two other innovations: they liked the organic variant (6.20) as much as the traditional one, but they gave a lower score to the spicy variant (5.06). In the expectancy condition, as observed in Warsaw, the variant in a biodegradable packaging was the most liked (6.27); this liking score was not significantly higher than the scores of the low-salt and the spicy variants (6.00 and 5.82, respectively) but was significantly higher than the score obtained by the traditional variant (5.63). Contrary to what was observed in Warsaw, the organic variant was as much liked (5.97) as the other innovations. In the full information condition as in the blind condition, the most liked variant was the one in a biodegradable packaging (6.45) and the least liked was the low-salt variant (6.04). The traditional variant and the two other innovations (i.e. organic and spicy variants) obtained intermediate values of liking scores.

\section{Willingness to pay (WTP)}

Mean reservation price elicited by BDM auctions are presented in Figure 3 and Figure 4. Price levels for a $300 \mathrm{~g}$ package of Kabanos range between 5.59 PLN and 7.95 PLN on average across sessions in both cities. The price range corresponds to the average market prices for non-organic Kabanos but are far below the prices for organic ones that were offered with the price of 20 PLN $( \pm 5 €)$ per $300 \mathrm{~g}$ at the time of the experiment. The price levels for organic Kabanos reflect also the immature character of the Polish organic food market, where there is a limited availability of organic meat and the price premium for such products is relatively high.

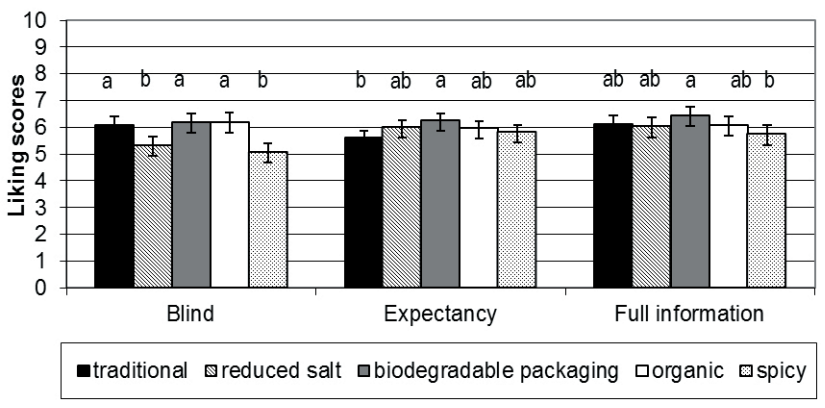

FIGURE 2. Liking of Kabanos in the three information conditions in Cracow, $(n=119)$ : means $\pm 95 \% \mathrm{CI}$, values with different letters are significantly different ( $\mathrm{p} \leq 0.05$, Bonferroni tests).

A significant variant effect was observed in Warsaw for each test condition. The effect was less important than for the liking scores in particular for the blind and expectancy conditions $\left(\mathrm{F}_{4.404}=3.65,4.76\right.$, and 6.89 , and $\mathrm{p}<0.0062$, $\mathrm{p}=0.0009$, and $\mathrm{p}<0.0001$, respectively for blind, expectancy and full information conditions). However, the ranking of the variants in terms of reservation prices was quite similar to the ranking in terms of liking as shown in Figure 3.

In the blind condition, none of the innovations obtained a significantly higher reservation price than the traditional variant. As for hedonic liking, the organic variant was less well evaluated in terms of reservation price than the traditional variant (6.49 PLN and 7.28 PLN, respectively). Contrary to what was found for the liking scores, the low-salt variant (6.93 PLN) was not significantly depreciated compared to the traditional variant in terms of reservation price. As for the liking scores, the patterns of results between the blind and the expectancy conditions differed. In the expectancy condition, consumers were willing to pay the highest price (7.95 PLN) for the variant in biodegradable packaging; this reservation price was not significantly higher than the reservation prices of the low-salt and the spicy variants (7.72 and 7.82 PLN, respectively) but was significantly higher than the reservation price given to the traditional variant (7.12 PLN) and to the organic variant (7.16 PLN). In the full information condition, consumers were also willing to pay the highest price (7.94 PLN) for the variant in a biodegradable packaging as in the expectancy condition; this reservation price was not significantly higher than the reservation price of the spicy variant (7.43 PLN) or of the traditional variant (7.28 PLN). The lowest reservation prices were given to the low-salt and to the organic variants (6.83 and 6.80 PLN, respectively) but these reservation prices were not significantly lower than the prices of the traditional variant.

In Cracow, the variant effect for the reservation price was significant only in the blind condition $\left(\mathrm{F}_{4.472}=5.73,2.37\right.$, and 1.25 , and $p<0.0002, p=0.0517$, and $p=0.29$, respectively for blind, expectancy and full information conditions). This means that even if participants gave different liking scores to the different variants of Kabanos in expectancy and full information conditions, they valued them similarly. This is particularly noticeable for the variant in a biodegradable packaging for which the participants in Cracow had higher expectations but were not ready to pay more than for the traditional vari- 


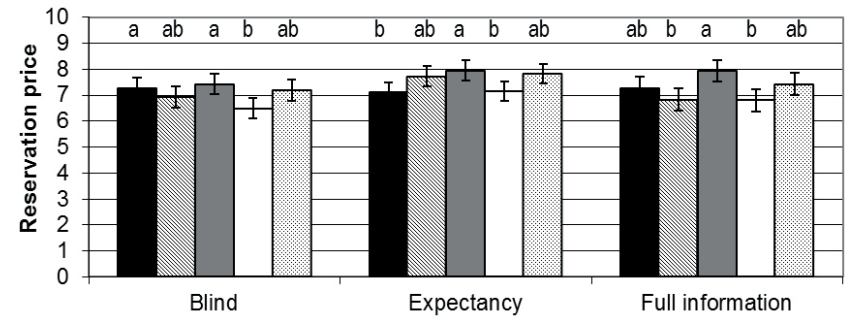

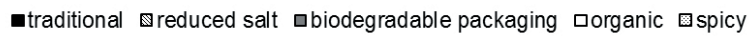

FIGURE 3. Reservation prices for Kabanos in the three information conditions in Warsaw $(n=102)$ : means $\pm 95 \%$ CI, values with different letters are significantly different ( $\mathrm{p} \leq 0.05$, Bonferroni tests).

ant. In the blind condition, as in Warsaw none of the innovations obtained a significantly higher reservation price than the traditional variant as shown in Figure 4. The spicy variant which was less liked than the traditional variant was also less well valued (5.60 and 6.15 PLN, respectively). Contrary to what was found for the liking scores, the low-salt variant (5.79 PLN) was not significantly depreciated compared to the traditional variant in terms of reservation price.

Participants in Warsaw and Cracow have similar reactions towards the low salt variant that they liked less than the traditional variant in the blind condition. However, in both cities participants did not give significantly lower reservation price for this innovation. Participants of the two cities had also similar reactions towards the variant in a biodegradable packaging giving it higher liking score in the expectancy condition. However, only participants in Warsaw were ready to pay more for this innovation than for the traditional variant. The two cities had different hedonic reactions towards the two other innovations, i.e. the organic and the spicy variant: the organic variant being less liked than the traditional variant in Warsaw while the participants in Cracow less liked the spicy variant.

\section{Consumers' perception of traditional food and attitudes towards innovation in TFPs}

The results show that participants from Cracow have a more positive image of TFP than consumers in Warsaw (5.43 and 5.89, respectively in Warsaw and Cracow, $\mathrm{t}=-2.94$, $\mathrm{p}=0.004)$ and associate more traditional food with high overall quality (5.36 and 5.87, respectively in Warsaw and Cracow, $\mathrm{t}=-2.71, \mathrm{p}=0.008)$ while consumers in Warsaw are more convinced that traditional food has positive impact on animal welfare (4.01 and 3.54, respectively in Warsaw and Cracow, $\mathrm{t}=1.97, \mathrm{p}=0.05$ ). However, when it comes to organic products, consumers in Cracow do not differ from consumers in Warsaw in their perception of overall quality (5.75 and 5.93, respectively in Warsaw and Cracow, $\mathrm{t}=-1.06, \mathrm{p}=0.286$ ) but they scored significantly higher on sensory aspects of organic food like "better taste" (5.20 and 5.62, respectively in Warsaw and Cracow, $\mathrm{t}=-2.16, \mathrm{p}=0.031$ ), "special taste" (4.77 and 5.23, respectively in Warsaw and Cracow, $\mathrm{t}=-2.53$, $\mathrm{p}=0.012)$ and "better appearance" (4.58 and 5.04, respectively in Warsaw and Cracow, $\mathrm{t}=-2.28, \mathrm{p}=0.024)$ than consumers in Warsaw. Their image of organic food seems driven by conviction that organic food has superior sensory quality. This could explain why the participants in Cracow gave higher ex-

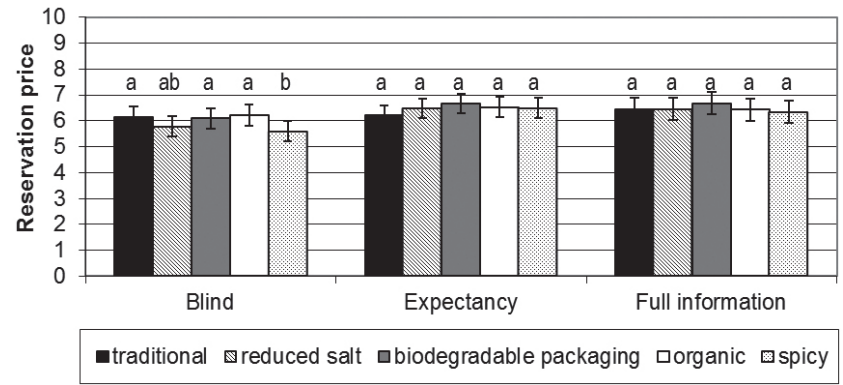

FIGURE 4. Reservation prices for Kabanos in the three information conditions in Cracow $(n=119)$ : means $\pm 95 \% \mathrm{CI}$, values with different letters are significantly different ( $\mathrm{p} \leq 0.05$, Bonferroni tests).

pected liking scores to the organic variant despite the fact that they did not associate more an innovation using meat from organic production with Kabanos than participants from Warsaw (Figure 5). When asked to indicate to what extent they associate each innovation proposed with Kabanos, participants from Warsaw and Cracow gave the highest score to Kabanos in an environmental friendly packaging in relation with their liking scores and reservation prices observed in the expectancy condition. The lowest score was given to an innovation with addition of new/unusual ingredients. Looking at the liking scores and reservation prices given to the spicy variant, it seems that spices were probably not considered as an unusual ingredient in Kabanos. Participants in Warsaw declared to associate more an innovation concerning a lower level of salt with Kabanos than participants from Cracow (5.50 and 5.05, respectively for Warsaw and Cracow, $\mathrm{t}=2.00, \mathrm{p}=0.05$ ). However, this does not result in a different pattern of liking or reservation prices in the expectancy condition.

Concerning reduction in salt, participants were also asked about their general attitude and habits. Almost all participants in both cities $(94.0 \%)$ declared that salt consumption should be reduced, a majority $(74.0 \%)$ declared that they reduce their salt consumption but only a tiny percentage (3.7\%) declared to buy always food with lower level of salt.

\section{DISCUSSION}

Polish consumers are inclined to accept innovation in traditional meat products but their willingness to accept innovation varies depending on the type of innovation proposed. Biodegradable packaging seems to be the most welcome innovation regardless region and experimental conditions. This is in line with results showing that environmental friendliness is a positive driver of TFP development in Poland [Almli et al., 2011a]. This is also coherent with the fact that Polish consumers scored highest on environmental friendliness while assessing traditional food image comparing to other European countries [Guerrero et al., 2009]. The findings of Guerrero et al. [2009] showed also that consumers are open to packaging and convenience-oriented innovations, on the condition that they do not modify the fundamental intrinsic characteristics of the product. In case of Kabanos in biodegradable packaging this condition was met since the recipe was not altered. Despite the high liking scores for Kabanos in biodegradable packaging, consumers in Cracow are not ready to pay more for such variant. 


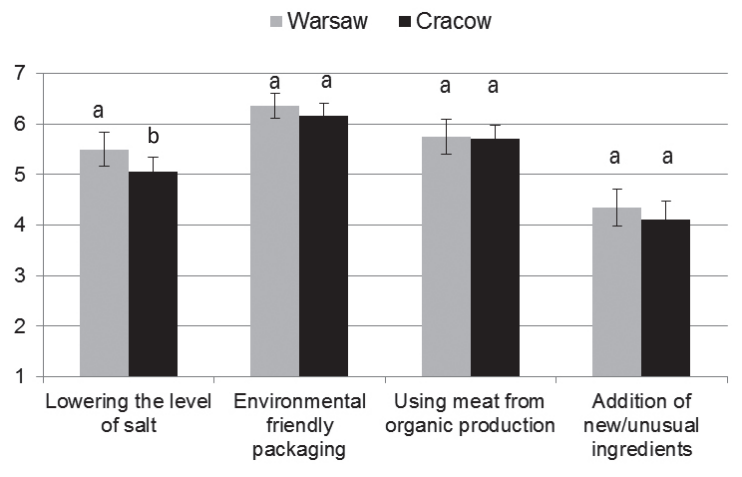

FIGURE 5. Association of the studied innovation with Kabanos in both cities (means $\pm 95 \% \mathrm{CI}$, values with different letters are significantly different ( $\mathrm{p} \leq 0.05$, t-tests). Assessments on 7-point agreement scale where $1=$ "I do not associate this innovation with Kabanos at all" and 7 means "I associate this innovation very much with Kabanos".

The regional differences do not play much role in assimilation of global trends for environmental friendly packaging but may imply differentiated approaches in developing pricing strategies for SME operating on these regional markets.

The results of Guerrero et al. [2009] reveal also that the changes in sensory quality such as modified flavours are not welcomed in traditional foods. As a result the proposed innovation related to sensory properties like lowering the salt level might be perceived by consumers as a threat to the authenticity of TFP. The low acceptance of reduced salt variant of Kabanos might also result from reluctance to lower salt consumption as reported in cross cultural studies among European consumers [Newson et al., 2013]. Another issue is the familiarity that is much more associated with motives to consume traditional food than healthiness [Pieniak et al., 2009]. Reduced salt Kabanos might be despite its health benefits a market failure due to inferior and unfamiliar taste properties. This is also reflected in research of Vanhonacker et al. [2010b] who found out that European traditional food consumers accept innovations that highlight the authenticity and origin of traditional foods and improve their shelf-life, but reject innovations that may affect the sensory properties. Vanhonacker et al. [2013] verified to what extent the perceived impact of the innovation on the traditional character contributed to the acceptance of innovation. Depending on the type of innovation, the acceptance was related to a reinforcement of the traditional character (e.g. a label that guarantees the origin of the raw material) or to benefits that either outweighs the importance of the traditional character or improve negative attributes associated with the traditional character like reduction of fat content [Vanhonacker et al., 2013]. Despite a positive attitude towards salt reduction, consumers in Warsaw and in Cracow did not give high liking scores and reservation prices to the low salt variant; this is certainly due to their low appreciation of this variant in the blind condition meaning that they did not like its sensory properties. Consumers in Warsaw accepted quite well some sensory modifications in Kabanos since they gave quite high scores and reservation prices to the spicy variant. On the contrary, the spicy variant of Kabanos tended to be disapproved in Cracow as revealed by the liking scores and reservation prices. The results for these participants are in line with Kühne et al. [2010] who found that moderate and low acceptance scores were found for innovations in TFP that change the conformity of the product and that combine existing ingredients into new products.

The main difference between the two regions in the acceptance of all innovative variants refer to the organic product which was more liked and more valued in Cracow than in Warsaw. Adding organic ingredients or using organic meat and complying with organic processing standards should result in added value. Poles perceive organic food as healthy and safe [Żakowska-Biemans, 2011] and using organic ingredients could reinforce the image of traditional food as a "healthy" product. According Kühne et al. [2010] the use of organic raw material in TFP were valued more positively, corresponding with the increased variety-seeking behaviour of consumers and the positive image of organic in terms of health and artisanal production methods. This issue needs further consideration to asses if organic and traditional are complementary or contradictory concepts in Polish consumers' mind. In general, Polish consumers' have high expectation towards organic food products [Żakowska-Biemans, 2011]. Using organic meat and organic spices in Kabanos production should result in similar liking scores to traditional variant in blind condition but this was not the case in Warsaw. Another important aspect is the immature character of Polish organic market and the shortage of organic meat. As a result processors face difficulties related to quantity and consistent quality of organic meat that might affect sensory attributes of the end product. Provision of information on organic origin in the expectancy and full information condition did not affect the liking scores of participants in Warsaw. As Napolitano et al. [2010] pointed out information about organic farming can be a major determinant of beef liking, thus providing a potential tool for meat differentiation to traditional farms. Moreover, consumers in the study of Napolitano et al. [2010] showed a willingness to pay for organic beef higher than the suggested price, the latter corresponding to the local commercial value for organic beef. Our data shows that consumers in Cracow despite their liking of organically produced Kabanos are not ready to pay price premium for such variant. The maximum price levels for organic Kabanos are much below the market prices in both regions and suggest that organic origin of ingredients used in traditional food processing will not contribute to added value.

\section{CONCLUSIONS}

The continuous development and launch of new food products are two major factors of companies' long-term success. In the increasingly globalising food market, innovation is a key strategic tool for SMEs operating in the TFP sector to achieve competitive advantage. The results of the hedonic evaluation and experimental auctions suggest that the traditional food industry in Poland should focus more on innovation related to extrinsic attributes like e.g. environmental friendly packaging since they seem to be an important driver for increasing market shares regardless of the regional differences observed. Organic production, despite its environmental benefits, is less valued than environmental friendly packaging and particularly consumers in Warsaw were sceptical towards organically produced 
Kabanos. The results suggest also that Polish consumers are less inclined to accept innovation in TFP related to intrinsic product attributes and particularly sensory quality. As the result the proposed innovation related to lowering the salt level despite its potential health benefits might be perceived by consumers as a threat to the authenticity of traditional sausages, a key credence attribute of traditional food. Altering sensory properties of traditional sausages with additional ingredients to attract consumers seeking for sensory sensations is in line with new market trends but consumers from Warsaw seem to be more inclined to assimilate such trends while consumers in Cracow appreciate less such innovations. Our results have also some managerial implications relevant for the companies operating in the traditional food sector. Information from studies combining hedonic evaluation and economic experiments give more insights into expected and experienced food liking and is particularly pertinent to food manufacturers and distributors to support successful introduction of innovation. This study shows also that BDM auction mechanism combined with hedonic liking is effective in eliciting significant differences in consumer valuations for different variants of food products. Our results confirm previous studies and suggest that when innovations are applied to TFP their degree of acceptance is strongly dependent on the type of innovation concerned. Packaging innovations that are in line with an emerging trend of environmental sustainability seem to be the most welcome. The outcomes of our research show also that companies operating in TFP market should be more attentive to the sensory improvements of TFP since any modification of sensory properties regardless its potential benefits might result in lower appreciation of Kabanos. Regional differences in acceptance of innovative variants of Kabanos are particularly visible when it comes to organic and spicy variant of Kabanos. Consumers in Cracow were fairly positive towards Kabanos produced from organic meat but not ready to pay more for it while consumers in Warsaw appeared rather sceptical, that was reflected in their liking scores and reservation prices. Therefore, our results have also implications for operators in the organic food sector. To increase the acceptance of traditional meat products produced with organic ingredients other benefits resulting from organic production methods like animal welfare should be more pronounced because consumers in Warsaw seem to be more concerned with such ethical attributes. The observed regional differences pose some challenges on emerging Polish traditional food sector since they require tailored made communication and pricing strategies respecting differences observed in liking and reservation prices for innovative variants of TFP. The study has also some limitations related to the generalizability of the results to a broader population. Further research is needed to explore consumers' drivers of liking and WTP for traditional meat products in other markets and regarding other type of innovation to support product differentiation.

\section{ACKNOWLEDGEMENTS}

This study was supported by the TRUEFOOD - "Traditional United Europe Food" - an Integrated Project financed by the European Commission under the 6th Framework Programme (Contract n ${ }^{\circ}$ FOOD-CT-2006-016264). The in- formation in this document reflects only the authors' views and the Community is not liable for any use that may be made of the information contained therein.

\section{REFERENCES}

1. Almli V.L., Naes T., Enderli G., Sulmont-Rosse C., Issanchou S., Hersleth M., Consumers' acceptance of innovations in traditional cheese. A comparative study in France and Norway. Appetite, 2011a, 57, 110-120.

2. Almli V.L., Verbeke W., Vanhonacker F., Naes T., Hersleth M., General image and attribute perceptions of traditional food in six European countries. Food Qual. Prefer., 2011b, 22, 129-138.

3. Becker G., De Groot M.H., Marschak J., Measuring utility by a single-response sequential method. Behav. Sci., 1964, 9, 1, 226-232.

4. Borowska A., Referat na konferencji „Rynek tradycyjnej żywności o uznanej jakości", Ożarów Mazowiecki, 10-11 December 2007 (in Polish, unpublished).

5. Cayot N., Sensory quality of traditional foods. Food Chem., 2007, 101, 1, 154-162.

6. Gellynck X., Kühne B., Innovation and collaboration in traditional food chain networks. J. Chain Net. Sci., 2008, 8, 2, 121-129.

7. Gellynck X., Molnár A., Chain governance structures: The European traditional food sector. Brit. Food J., 2009, 11, 8, 762-775.

8. Guerrero L., Claret A., Verbeke W., Enderli G., Zakowska-Biemans S., Vanhonacker F., Issanchou S, Sajdakowska M, Signe Granli B., Scalvedi L., Contel M., Hersleth M., Perception of traditional food products in six European countries using free word association. Food Qual. Prefer., 2010, 21, 2, 225-233.

9. Guerrero L., Guardia M.D., Xicola J., Verbeke W., Vanhonacker F., Zakowska-Biemans S., Sajdakowska M., Sulmont-Rosse' C., Issanchou S., Contel M., Scalvedi M.L., Granli B.S., Hersleth M., Consumer-driven definition of traditional food products and innovation in traditional foods. A qualitative cross-cultural study. Appetite, 2009, 52, 345-354.

10. Gutkowska K., Żakowska-Biemans S., Sajdakowska M., Preferencje konsumentów w zakresie możliwych do zastosowania innowacji w produktach tradycyjnych. Żywn. Nauk Technol. Jakość, 2009, 64, 115-125 (in Polish; English abstract).

11. Gutkowska K., Murawska A. Poziom życia ludności a wielkość i struktura spożycia żywności w aspekcie regionalnym. Handel Wewnętrzny, 2013, 4, 345, 47-60 (in Polish; English abstract).

12. Hofstede G., Culture's consequences - comparing values, behaviours, institutions and organizations across nations', 2001, London, Sage Publications.

13. Jordana J., Traditional foods: Challenges facing the European food industry. Food Res. Int., 2000, 33, 3-4, 147-152.

14. Kabanos sausage - Traditional Speciality Guaranteed, available at: [http://www.minrol.gov.pl/eng/content/view/full/32319]. Accessed January 2015.

15. Kühne B., Vanhonacker F., Gellynck X., Verbeke W., Innovation in traditional food products in Europe: Do sector innovation activities match consumers' acceptance? Food Qual. Prefer., 2010, 21, 629-638.

16. Napolitano F., Braghieri A., Piasentier E., Favotto S., Naspetti S., Zanoli R., Effect of information about organic production on beef liking and consumer willingness to pay. Food Qual. Prefer., 2010, 21, 2, 207-212. 
17. Newson R.S., Elmadfa I., Biro Gy., Cheng Y., Prakash V., Rust P., Barna M., Lion R.,. Meijer G.W., Neufingerl N., Szabolcs I., van Zweden I., Yang R. Y., Feunekes G.I.J., Barriers for progress in salt reduction in the general population". Appetite, 2013, 71, 22-31.

18. Official Journal of the European Union Commission implementing regulation [EU] No 1044/2011 of 19 October 2011 entering a name in the register of the traditional specialities guaranteed (Kabanosy TSG).

19. Pieniak Z., Verbeke W., Vanhonacker F., Guerrero L., Hersleth M., Association between traditional food consumption and motives for food choice in six European countries. Appetite, 2009, 53, 1, 101-108.

20. Polish registry, "Register of traditional foods", Polish Ministry of Agriculture and Rural Development. [http://www.minrol.gov. pl/index.php?/pol/Jakosczywnosci/Produkty-regionalne-i-tradycyjne/Lista-produktow-tradycyjnych], Accessed January 2015.

21. Sojkin B., Małecka M., Olejniczak T., Bakalarska M., Konsument wobec innowacji produktowych na rynku żywności, 2009, Wydawnictwo Uniwersytetu Ekonomicznego w Poznaniu. Poznań (in Polish).

22. Trichopoulou A., Soukara S., Vasilopoulou E., Traditional foods: A science and society perspective. Trends Food Sci. Tech., 2007, $18,8,420-427$.
23. Vanhonacker F., Kühne B., Gellynck X., Guerrero M., Hersleth M., Verbeke W., Innovations in traditional foods: Impact on perceived traditional character and consumer acceptance. Food Res. Int., 2013, 54, 1828-1835.

24. Vanhonacker F., Lengard V., Hersleth M., Verbeke W., Profiling European traditional food consumers. Brit. Food J., 2010a, 112, 8, 871-886.

25. Vanhonacker F., Verbeke W., Guerrero L., Claret A., Contel M., Scalvedi M.L., Zakowska-Biemans S., Gutkowska K., SulmontRossé C., Raude J., Granli B.S., Hersleth M., How European consumers define the concept of traditional food: Evidence from a survey in six countries. Agribusiness, 2010b, 26, 4, 453-476.

26. Weichselbaum E., Benelam B., Soares Costa H., Traditional foods in Europe. In European Food Information Ressource (EuroFIR) consortium, EU 6th framework food quality and safety thematic priority. Contract FOOD-CT-2005- 513944. 2009 [http://www. eurosfaire.prd.fr/7pc/documents/1263815283_traditional_foods_ can_sustain_european_cultures.pdf], accessed December 2015.

27. Zakowska-Biemans S., Polish consumer food choices and beliefs about organic food. Brit. Food J., 2011, 113, 1, 122-137.

Submitted: 8 October 2015. Revised: 5 February and 15 March 2016. Accepted: 16 March 2016. Published on-line: 12 April 2016. 
